\title{
Artikel
}

\section{De nieuwe Richtlijnen Vereffening nalatenschappen en Handleiding erfrechtprocedures kantonrechter: verzoeken tot aanwijzingen ex artikel 4:210 lid 1 BW niet (meer) mogelijk}

Mr. J.Th.M. Diks en mr. dr. N. Lavrijssen*

\section{Inleiding}

De praktijk wachtte in spanning op de aangepaste versies van de Richtlijnen Vereffening nalatenschappen en de Handleiding erfrechtprocedures kantonrechter. De Expertgroep Erfrecht van het Landelijk Overleg Vakinhoud Civiel, Kanton en Toezicht (LOVCK\&T) keurde de nieuwe handleiding (versie 8.0) ${ }^{1}$ en de nieuwe richtlijnen (versie 3.0) ${ }^{2}$ op 13 februari 2020 goed. De verwachting was dat de handleiding wat uitgebreider verbeterd en angevuld zou worden. Te denken valt bijvoorbeeld aan aanpassing van de algemene opmerkin-

* Mr. J.Th.M. Diks is advocaat en vereffenaar bij Advocaten Familie- \& Erfrecht te Eindhoven en Utrecht en docent bij diverse opleidingsinstellingen. Hij is medeontwikkelaar van en docent bij de Specialisatieopleiding Vereffening Nalatenschappen van Familie- \& Erfrecht Instituut Nederland. Mw. mr. dr. N. Lavrijssen is medewerker bij het wetenschappelijk bureau van Advocaten Familie- \& Erfrecht te Eindhoven en Utrecht. Zij is tevens als docent en onderzoeker verbonden aan de Juridische Hogeschool Avans-Fontys te Tilburg en 's-Hertogenbosch.

1. Zie www.rechtspraak.nl/SiteCollectionDocuments/handleiding-erfrecht procedures-kantonrechter.pdf.

2. Zie www.rechtspraak.nl/SiteCollectionDocuments/richtlijnen-vereffe ning-nalatenschappen.pdf. gen. ${ }^{3}$ Ook had een toelichting waarom de benoeming van de vereffenaar in deze handleiding is opgenomen, terwijl dit niet tot de competentie van de kantonrechter behoort (of het verwijderen van deze procedure uit de handleiding), ${ }^{4}$ voor de hand gelegen. Daarnaast was het wenselijk geweest wanneer de betreffende procedures uit Boek III, titel 2 van het Wetboek van Burgerlijke Rechtsvordering ( $\mathrm{Rv}$ ) ('Van procedures betreffende een nalatenschap of een gemeenschap'), waarin onder andere de procedure tot het bevel boedelbeschrijving is geregeld, zouden zijn toegevoegd. Het zou goed zijn als de volgende wijziging weer zo'n uitgebreide zou worden als in 2017. ${ }^{5}$ De expertgroep koos er nu voor een beperkt aantal artikelen aan te passen. In de handleiding worden aanpassingen gedaan die zien op griffierechten, prevereffeningskosten, de artikelen 4:191 tot en met 4:193 van het Burgerlijk Wetboek (BW) en de door een rechter te geven aanwijzingen. In de richtlijnen gaat het ook om aanpassingen betreffende de pre-vereffeningskosten en de aanwijzingen die een rechter kan geven. Deze aanpassingen volgen uit de aanpassingen op de handleiding. De aanpassingen die gaan over aanwijzingen op grond

3. Voor suggesties zie J.Th.M. Diks, Procederen bij de kantonrechter in erfrechtzaken: de nieuwe Handleiding erfrechtprocedures kantonrechter, TE 2018, afl. 3, p. 58.

4. Zie ook Diks, Procederen bij de kantonrechter in erfrechtzaken, p. 60.

5. Toen is er overigens heel wat achterstallig werk ingehaald, de versie van voor 2017 dateerde van 10 november 2008. 
van artikel 4:210 lid $1 \mathrm{BW}$ springen het meest in het oog en zijn onderwerp van deze bijdrage.

Op grond van artikel 4:202 lid $1 \mathrm{BW}$ wordt een nalatenschap vereffend wanneer deze nalatenschap door een of meer erfgenamen beneficiair is aanvaard (sub a) (en er geen sprake is van een van de uitzonderingen op deze regel) of wanneer de rechtbank een vereffenaar heeft benoemd (sub b). Zowel de erfgenaam-vereffenaar als de door de rechtbank benoemde vereffenaar is verplicht om aan de kantonrechter alle door hem gewenste inlichtingen te verschaffen en om diens aanwijzingen bij de vereffening op te volgen. Dat is geregeld in artikel 4:210 lid $1 \mathrm{BW}$. Op grond van de letterlijke tekst van dit artikel gaat het om een ambtshalve aanwijzing door de kantonrechter, waar nader op ingegaan wordt in paragraaf 2 van deze bijdrage. Naast deze ambtshalve aanwijzing kwam het tot nu toe in de praktijk ook regelmatig voor dat de vereffenaar (of een schuldeiser of een erfgenaam) zelf verzocht om een aanwijzing aan de kantonrechter. Deze gang van zaken wordt nader beschreven in paragraaf 3 . De vorm waarin de aanwijzing tot nu toe werd gegeven, en hoe deze onder de nieuwe richtlijnen zal worden gegeven, staat centraal in paragraaf 4. Paragraaf 5 sluit deze bijdrage af.

\section{Ambtshalve aanwijzing}

Artikel 4:210 BW en de daaruit voortvloeiende bevoegdheden van de kantonrechter zijn in het leven geroepen om de kantonrechter handvatten te bieden om toezicht uit te kunnen oefenen op de vereffening. Hierbij is het goed om in ogenschouw te nemen dat de kantonrechter zijn toezichtfunctie pas zal kunnen uitoefenen zodra hem bepaalde inlichtingen hebben bereikt aangaande de vereffening van de nalatenschap. Denk bijvoorbeeld aan de situatie waarin een schuldeiser van een nalatenschap de kantonrechter aanschrijft in verband met een vordering die hij op de nalatenschap heeft of naar aanleiding van berichtgeving van de vereffenaar aan de kantonrechter. Pas op dat moment is de vereffening van de nalatenschap bij de kantonrechter bekend. Het is immers niet de kantonrechter die een vereffenaar benoemt, maar de rechtbank. En wanneer de erfgenamen de vereffenaars zijn, dan is dit niet op grond van een benoeming door een rechter, maar van rechtswege op grond van artikel 4:195 lid $1 \mathrm{BW}$.

Overigens wordt het toezicht op de vereffenaar niet altijd door de kantonrechter uitgeoefend. Op grond van artikel 4:208 lid 1 BW kan de rechtbank bij de benoeming van een vereffenaar (of bij latere beschikking) een van haar leden tot rechter-commissaris in die vereffening benoemen. Lid 2 sub a van artikel 4:208 BW bepaalt vervolgens dat de bevoegdheden die op grond van de vereffeningsafdeling normaal gesproken toekomen aan de kantonrechter, in dat geval worden uitgeoefend door de benoemde rechter-commissaris, tenzij de wet anders bepaalt.
Daarbij verdient opmerking dat de taak van de kantonrechter of rechter-commissaris bij de vereffening vanwege de aanwijzingsbevoegdheid van artikel 4:210 lid 1 $\mathrm{BW}$ ruimer is dan de taak van de rechter-commissaris in een faillissement. In faillissement houdt de rechter-commissaris op grond van artikel 64 e.v. van de Faillissementswet $\left(\mathrm{F}_{\mathrm{w}}\right)$ slechts toezicht op de curator. De reden hiervoor is gelegen in het feit dat een vereffenaar niet altijd een deskundige is, terwijl dit wel het geval is bij een faillissementscurator. ${ }^{6}$ Juist wanneer vereffenaars geen ter zake kundigen zijn, ligt controle door een kundig jurist voor de hand, aldus de parlementaire geschiedenis. $^{7}$

Hierbij dienen wel twee kanttekeningen te worden geplaatst. In de eerste plaats verdient opmerking dat de curator in een faillissement voor bepaalde handelingen een machtiging van de rechter-commissaris behoeft. Op grond van artikel 68 lid $2 \mathrm{Fw}$ heeft de curator deze machtiging nodig wanneer hij in rechte wil optreden, maar bijvoorbeeld ook voor het opzeggen van een huurovereenkomst of arbeidsovereenkomst op grond van artikel 39 respectievelijk artikel $40 \mathrm{Fw}$. Ook heeft de curator op grond van artikel $104 \mathrm{FW}_{\mathrm{W}}$ voor het sluiten van een vaststellingsovereenkomst of het treffen van een schikking goedkeuring van de rechter-commissaris nodig. Daarmee omvat de taak van de rechter-commissaris in een faillissement meer dan alleen het houden van toezicht op de curator op grond van artikel 64 e.v. Fw. Er zou zelfs gezegd kunnen worden dat de machtigingsbevoegdheid van de rechter-commissaris verder gaat dan de aanwijzingsbevoegdheid van de kantonrechter ten opzichte van de vereffenaar op grond van artikel 4:210 lid $1 \mathrm{BW}$. In de tweede plaats is het belangrijk op te merken dat het hiervoor genoemde verschil tussen een professionele curator enerzijds en een niet altijd ter zake deskundige vereffenaar anderzijds ook deels achterhaald is, nu er anno 2020 voornamelijk professionele vereffenaars door de rechtbank worden benoemd. Van een professionele vereffenaar mag veel deskundigheid worden verwacht bij de vereffening van een nalatenschap. Uiteraard geldt dit niet (altijd) voor een erfgenaam die de nalatenschap beneficiair heeft aanvaard, en op die grond de vereffenaar van een nalatenschap is.

Artikel 4:210 lid 1 BW geeft zelf geen antwoord op de vraag in welke situaties de kantonrechter of rechtercommissaris een aanwijzing kan geven. Inmiddels is in lagere rechtspraak een criterium ontwikkeld: de kantonrechter geeft slechts ambtshalve aanwijzingen indien daarvoor 'gegronde redenen' bestaan. ${ }^{8}$ Uit de lagere rechtspraak blijkt dat het erg afhankelijk is van de feiten en omstandigheden of er sprake is van gegronde redenen. Een voorbeeld van een procedure waarin een ambtshalve aanwijzing is gegeven door de kantonrechter aan de vereffenaar is de uitspraak van de rechtbank Limburg van 14 maart $2017,{ }^{9}$ waarin de kantonrechter

\footnotetext{
T\&C BW, art. 4:210 BW, aant. 1.

MvA II, Parl. Gesch. Boek 4, p. 995

T\&C BW, art. 4:210 BW, aant. 1.

Rb. Limburg 14 maart 2017, ECLI:NL:RBLIM:2017:2296.
} 
de vereffenaar de aanwijzing geeft bepaalde werkzaamheden uit te voeren (onder andere het nagaan of een paard tot de nalatenschapsboedel behoort of niet) en daarvan verslag uit te brengen aan de erfgenamen en de kantonrechter. Uit gepubliceerde uitspraken blijkt dat aanwijzingen regelmatig worden gegeven in de vorm van een beschikking. In de praktijk worden aanwijzingen evenwel ook vaak in briefvorm gegeven. Aanwijzingen in briefvorm worden - in tegenstelling tot geselecteerde aanwijzingen in de vorm van een beschikking - niet gepubliceerd op de website van de Rechtspraak. Bij de vorm waarin een aanwijzing wordt gegeven, staan we stil in paragraaf 4 van deze bijdrage.

\section{Verzoek om aanwijzing door vereffenaar (of andere belanghebbende)}

In het verleden hebben vereffenaars (en andere belanghebbenden) veelvuldig zelf verzocht om een aanwijzing op grond van artikel 4:210 lid $1 \mathrm{BW}$. In de beginperiode werden door benoemde vereffenaars ook veel aanwijzingen verzocht waarvoor artikel 4:210 lid $1 \mathrm{BW}$ niet bedoeld is. Het ging daarbij bijvoorbeeld niet om aanwijzingen betreffende een bepaalde te volgen strategie, het voeren van een procedure of het aangaan van een vaststellingsovereenkomst, maar om bijvoorbeeld aanwijzingen over standaardwerkzaamheden van de vereffenaar of de werking van bepaalde artikelen uit Boek 4 BW.

Hoewel de mogelijkheid om zelf een aanwijzing te verzoeken aan de rechter niet expliciet uit de wettekst zelf blijkt, lijkt uit de parlementaire geschiedenis naar voren te komen dat de wetgever deze mogelijkheid wel voor ogen heeft gehad bij de ontwikkeling van het nieuwe erfrecht. ${ }^{10}$ Uit lagere rechtspraak blijkt dat deze verzoeken van vereffenaars in het verleden veelvuldig in behandeling zijn genomen door de kantonrechter. Zo oordeelde de rechtbank Midden-Nederland op 21 april $2015^{11}$ bijvoorbeeld ${ }^{12}$ dat de kantonrechter op verzoek van de vereffenaar zelf een aanwijzing kan geven om verweer te voeren in een in de Verenigde Staten aanhangig gemaakte procedure. In deze procedure overwoog de kantonrechter dat er in dit geval sprake is van een gegronde reden voor het geven van een of meer

10. Parl. Gesch. Boek 4 BW, 2002, p. 1008. Zie ook Asser/Perrick 4 2017/615.

11. Rb. Midden-Nederland 21 april 2015, ECLI:NL:RBMNE:2015:2792, RFR 2015/103.

12. In de rechtspraak zijn meer voorbeelden van verzoeken van vereffenaars terug te vinden. Zie bijvoorbeeld Rb. Rotterdam 12 maart 2019, ECLI:NL:RBROT:2019:5484 (verzoek tot aanwijzing afgewezen; dient niet om nakoming van afspraken te vordeen), Rb. Rotterdam 8 november 2018, ECLI:NL:RBROT:2018:9083 (verzoek tot aanwijzing met betrekking tot eindafrekening), Rb. Rotterdam 5 september 2018, ECLI:NL:RBROT:2018:7592 (verzoek tot aanwijzing in verband met pauliana), Rb. Den Haag 1 september 2017, ECLI:NL:RBDHA:2017: 9802 (verzoek tot aanwijzing met betrekking tot uitoefenen optierecht) en Rb. Noord-Nederland 9 augustus 2017, ECLI:NL:RBNNE:2017:3158 (verzoek tot aanwijzing met betrekking tot rente na overlijdensdatum). aanwijzingen, aangezien de Amerikaanse vordering op de nalatenschap - die substantieel is - wordt betwist en de toewijzing van die vordering grote gevolgen zou kunnen hebben voor de nalatenschap. De kantonrechter geeft in deze zaak niet tot in detail aanwijzingen. Hij geeft bijvoorbeeld aan dat de vereffenaar verweer moet voeren in de Amerikaanse procedure, maar geeft geen aanwijzing met betrekking tot het te voeren verweer. Dat is aan de vereffenaar zelf, in overleg met zijn Amerikaanse advocaat, om te bepalen. ${ }^{13}$

Zoals in de vorige alinea is aangegeven, bestond de mogelijkheid tot het vragen van een aanwijzing aan de kantonrechter in het kader van een vereffening ook voor (andere) belanghebbenden. Die andere belanghebbende moest daarbij dan wel aannemelijk maken dat hij voldoende belang heeft voor het vragen van zo'n aanwijzing. Of dit belang aanwezig werd geacht, was afhankelijk van de concrete omstandigheden van het geval, en dus erg casuïstisch van aard.

Voor de toewijzing van een verzoek tot het geven van een aanwijzing door de kantonrechter was - net als voor de ambtshalve aanwijzing - vereist dat er sprake is van gegronde redenen. Dit blijkt uit lagere rechtspraak, zoals bijvoorbeeld in de uitspraak van de rechtbank Midden-Nederland van 24 juli 2015. ${ }^{14}$ Er zijn verschillende uitspraken waarin het verzoek tot het geven van aanwijzingen afgewezen is, omdat gegronde redenen ontbreken. Deze afwijzingen worden niet altijd gemotiveerd aan de hand van de feitelijke situatie. De uitspraak van de rechtbank Midden-Nederland van 24 juli 2015 is op dit punt illustratief. De kantonrechter overwoog in deze uitspraak het volgende:

'De kantonrechter is niet gebleken dat er sprake is van een gegronde reden voor het geven van aanwijzingen in de zin van artikel 4:210 lid $1 \mathrm{BW}$. Daarom zal de kantonrechter het verzoek tot het geven van aanwijzingen afwijzen.'

Met de komst van de nieuwe handleiding lijkt de praktijk van het indienen van verzoeken om aanwijzingen door vereffenaars (en anderen) verleden tijd, althans dat beoogt de expertgroep. In de handleiding wordt de visie van Perrick ${ }^{15}$ en Baetens, ${ }^{16}$ gebaseerd op een passage uit de parlementaire geschiedenis waarin naar voren komt dat een rechter 'op verzoek van een belanghebbende' aanwijzingen kan geven, ${ }^{17}$ uiteengezet. De expertgroep merkt op dat deze visie niet onomstreden is en verwijst daarbij naar een bijdrage van Lieber in dit tijdschrift. ${ }^{18}$ De expertgroep overweegt het volgende:

13. Rb. Midden-Nederland 21 april 2015, RFR 2015/103.

14. Rb. Midden-Nederland 24 juli 2015, ECLI:NL:RBMNE:2015:5819.

15. Asser/Perrick 4 2017/615

16. S.R. Baetens, De aanwijzing aan de vereffenaar op grond van artikel 4:210 lid 1 BW, TE 2018, afl. 2, p. 32.

17. Parl. Gesch. Boek 4 BW, 2002, p. 1008

18. J.H. Lieber, Toezicht op de vereffening door de rechter met bijzondere aandacht voor procesrechtelijke aspecten en eenduidigheid, TE 2019, afl. 1, p. 1-6. 
'Het volgen van de visie dat belanghebbenden een verzoek kunnen doen tot het geven van een aanwijzing, heeft verstrekkende gevolgen. Niet alleen staat het de kantonrechter niet meer vrij geen aanwijzing te geven (dat zal namelijk aangemerkt worden als een afwijzing), maar bovendien zal de beslissing (het al dan niet geven van de aanwijzing) vatbaar zijn voor hoger beroep. En daar wringt naar de mening van de expertgroep de schoen. Nog daargelaten of bij het opstellen van de memorie van antwoord voor ogen heeft gestaan dat met de woorden "op verzoek van" de mogelijkheid van een hoger beroep werd gecreëerd, acht de expertgroep dit onwenselijk indachtig het doel en de strekking van de vereffeningsprocedure. Deze procedure is er vooral toch op gericht een gecontroleerde afwikkeling tot stand te brengen, waarbij de kantonrechter zowel inhoud als voortvarendheid kan controleren doordat hij om inlichtingen kan vragen en aanwijzingen kan verstrekken. Een, of meerdere, mogelijk zelfs uitgelokte behandelingen van hoger-beroepszaken tijdens de vereffening zullen een voorspoedige afwikkeling niet ten goede komen. En dan drukken we ons voorzichtig uit. De mogelijkheid van hoger beroep zou van de mogelijkheid tot het geven van aanwijzingen zelf, een tandeloze tijger maken en bovenal leiden tot een zeer ongewenste mogelijkheid de afwikkeling van de vereffening ernstig te vertragen. De expertgroep is van mening dat deze mogelijkheid niet moet worden geboden aan belanghebbenden. De expertgroep beveelt daarom aan het bepaalde in artikel 210 zo uit te leggen dat belanghebbenden in een nalatenschap de kantonrechter op de hoogte kunnen stellen van feiten en omstandigheden die zouden kunnen leiden tot het geven van een aanwijzing. Het al dan niet geven van een aanwijzing betreft een discretionaire bevoegdheid van de kantonrechter, waar geen hoger beroep tegen open staat.'

Hieruit blijkt dat vereffenaars (en anderen) niet langer kunnen verzoeken om een aanwijzing bij de kantonrechter, maar dat zij wel een ambtshalve aanwijzing als het ware kunnen uitlokken door het geven van bepaalde inlichtingen op grond van artikel 4:210 lid $1 \mathrm{BW}$. De komst van de nieuwe handleiding zorgt op dit punt dus voor een opvallende breuk met de tot nu toe gangbare praktijk rondom het verkrijgen van een aanwijzing van de kantonrechter op verzoek. Overigens hoeft het voor de praktijk niet altijd uit te maken of een anwijzing wordt verzocht of wordt uitgelokt, omdat het gevolg (het verkrijgen van een aanwijzing of niet) in beide gevallen hetzelfde is. Bovendien zal de kantonrechter dezelfde toets hanteren: een aanwijzing zal alleen gegeven worden wanneer daar gegronde redenen voor zijn.

De expertgroep acht de letterlijke tekst van artikel 4:210 lid $1 \mathrm{BW}$ daarmee doorslaggevend en niet de in de parlementaire geschiedenis vermelde tekst dat de kantonrechter 'op verzoek van een belanghebbende' een aanwijzing kan geven. In onze optiek is voor dat argument op zich wel wat te zeggen. Formuleringen als 'op ver- zoek van' komen in het alledaags taalgebruik ook veel voor. Wij kunnen ons indenken dat de wetgever met deze zinsnede in de parlementaire geschiedenis niet gedoeld heeft op de juridische betekenis ervan, in die zin dat een verzoekschriftprocedure openstaat voor het verkrijgen van een aanwijzing van de kantonrechter, maar dat deze zinsnede als alledaags taalgebruik moet worden opgevat. Zou de wetgever wel voor ogen hebben gehad dat het hier om een verzoekschriftprocedure gaat, dan zou hij er waarschijnlijk voor hebben gekozen om dit nadrukkelijk in de wettekst op te nemen en artikel 4:210 lid $1 \mathrm{BW}$ op te nemen in de limitatieve opsomming van artikel $676 \mathrm{a} \mathrm{Rv}$ van beschikkingen waartegen geen hoger beroep kan worden ingesteld. Als we er tenminste van uitgaan dat de wetgever in dat geval zou vinden dat geen appel mogelijk is. Op artikel 676a Rv gaan we in de volgende paragraaf nader in.

Overigens plaatsen wij wel een kanttekening bij het argument van de expertgroep dat de mogelijkheid van hoger beroep de mogelijkheid tot het geven van aanwijzingen zelf tot een tandeloze tijger zou maken en zou leiden tot een zeer ongewenste mogelijkheid de afwikkeling van de vereffening ernstig te vertragen. Dit 'vertragingsargument' zou in onze optiek geen doorslaggevende reden mogen zijn om te concluderen dat geen hoger beroep mogelijk is. Een appel zorgt immers per definitie voor vertraging. Ons inziens zou dit argument, ondanks dat er veel voor te zeggen is dat de regelgeving moet zorgen voor een vlotte doorloop van de vereffening, niet zo zwaar mogen wegen dat voornamelijk om die reden de mogelijkheid tot het verzoeken om een aanwijzing niet zou moeten bestaan, althans niet zonder nadere onderbouwing. Wij vragen ons bijvoorbeeld af in hoeveel situaties er tot nu toe hoger beroep is ingesteld. Als het antal zaken waarin dit tot nu toe het geval is geweest, beperkt is, is het de vraag of dit argument voldoende zwaarwegend is om deze keuze te rechtvaardigen. Daar komt bij dat het in sommige situaties juist wenselijk kan zijn om het verzoek in hoger beroep nogmaals te laten beoordelen. Bovendien vragen wij ons af of effectief toezicht niet mogelijk zou zijn als op verzoek anwijzingen kunnen worden gegeven, en of de problemen - vanwege het ontbreken van de mogelijkheid om op verzoek aanwijzingen te geven - niet vooruitgeschoven worden naar de verzetprocedure. ${ }^{19}$ Ook zo'n verzetprocedure zorgt voor de nodige vertraging. Zou het niet beter zijn de procedure in eerste aanleg en in appel zo in te richten dat deze vlot verlopen, in plaats van het trage verloop als argument te geven voor het 'afschaffen' van de aanwijzing op verzoek? Wij realiseren ons dat als de kantonrechter de aanwijzing geeft, men drie maanden de tijd heeft om appel in te stellen. ${ }^{20}$ Ook vragen wij andacht voor het feit dat het erfrecht met de nieuwe richtlijnen en handleiding minder mogelijkheden lijkt te bieden voor belanghebbenden dan

19. Op grond van art. 4:218 lid 3 BW kan iedere belanghebbende tegen de rekening en verantwoording of tegen de uitdelingslijst in verzet komen.

20. Als de rechter-commissaris de aanwijzing geeft, bedraagt de appeltermijn conform art. $676 \mathrm{~b}$ Rv vijf dagen. 
het faillissementsrecht. Het faillissementsrecht is veel verder uitgekristalliseerd dan het 'vereffeningsrecht' in het erfrecht, maar vertoont, naast belangrijke verschillen, ook belangrijke overeenkomsten met de vereffeningsbepalingen uit het erfrecht. Een blik werpen op het faillissementsrecht is dus geen gek idee. Op grond van artikel 69 lid 1 Fw kunnen zowel schuldeisers als de gefailleerde bij verzoekschrift tegen elke handeling van de curator opkomen bij de rechter-commissaris of van de rechter-commissaris een bevel vragen inhoudende dat de curator een bepaalde handeling moet verrichten of juist iets moet nalaten te doen. Gelet op de vereffeningsbepalingen uit de $\mathrm{F}_{\mathrm{w}}$, die deels van overeenkomstige toepassing zijn verklaard op de vereffening in erfrechtkwesties, ${ }^{21}$ zou het wellicht meer voor de hand hebben gelegen dat de expertgroep juist had geconcludeerd dat het hier wel een verzoekschriftprocedure betreft. Op die manier zouden belanghebbenden in een nalatenschap immers - naar analogie van artikel 69 lid 1 $\mathrm{F}_{\mathrm{W}}$ - de kantonrechter kunnen vragen om de vereffenaar een aanwijzing te geven op grond van artikel 4:210 lid $1 \mathrm{BW}$.

\section{Wijze waarop een aanwijzing werd en wordt gegeven}

De wijze waarop een aanwijzing door de kantonrechter tot nu toe (ambtshalve of op verzoek) werd gegeven, is verschillend: sommige kantonrechters wezen een beschikking waarin ze de aanwijzing verwoordden, andere kantonrechters stuurden een brief. Ook als een kantonrechter geen aanwijzing wilde geven, werd dat soms kenbaar gemaakt in een beschikking, soms in een brief. Met de nieuwe handleiding lijkt een einde aan dit verschil te zijn gekomen. Daarin is bepaald dat het al dan niet geven van een aanwijzing een discretionaire bevoegdheid van de kantonrechter betreft, waar geen hoger beroep tegen openstaat.

Alhoewel dit niet expliciet uit de handleiding naar voren komt, lijkt hieruit de conclusie te kunnen worden getrokken dat een aanwijzing wordt gegeven bij brief en niet bij beschikking. Er lijkt dus geen sprake te zijn van een verzoekschriftprocedure. Tegen een beschikking zou immers in beginsel hoger beroep kunnen worden ingesteld, tenzij de uitspraak als niet appellabel zou zijn aangemerkt in artikel 676a Rv. Dit artikel geeft een limitatieve opsomming van beschikkingen ingevolge Boek 4 $\mathrm{BW}$, waartegen geen andere voorziening is toegestaan dan cassatie in het belang der wet. ${ }^{22}$ In deze opsomming worden enkele vereffeningsbepalingen genoemd, zoals artikel 4:211 lid 4 en 4:215 lid 2, tweede zin, BW, maar

21. Zie bijvoorbeeld art. 4:218 lid 5 BW, op grond waarvan bij de berekening van de vordering en het opmaken van de uitdelingslijst de regels van de Fw zo veel mogelijk van overeenkomstige toepassing zijn verklaard.

22. Vlas, in: Groene Serie Burgerlijke Rechtsvordering, art. 676a Rv, aant. 1. niet artikel 4:210 lid $1 \mathrm{BW}$. Als de aanwijzing bij beschikking zou worden gegeven, dan zou hiertegen dus hoger beroep ingesteld kunnen worden op grond van het $\mathrm{Rv}$, hetgeen door de expertgroep niet wenselijk wordt geacht. Overigens maakte de Hoge Raad al eerder uit dat de vorm van een beslissing niet doorslaggevend is voor de kwalificatie van de beslissing. ${ }^{23}$

De impliciete keuze voor het geven van een aanwijzing met behulp van een brief in plaats van een beschikking heeft tevens tot gevolg dat een kantonrechter niet verplicht is tot actie over te gaan. Dit past goed bij de eerdere overweging van de expertgroep dat de kantonrechter een discretionaire bevoegdheid heeft ter zake het al dan niet geven van een aanwijzing. Zou de beslissing in de vorm van een beschikking worden gegoten en zou een belanghebbende ook een verzoek om een aanwijzing kunnen indienen, dan is de kantonrechter verplicht om op het verzoek te beslissen. Hij mag in dat geval niet weigeren om uitspraak te doen. Dit komt niet overeen met de discretionaire bevoegdheid die de kantonrechter volgens de expertgroep op dit punt heeft.

Het is wel de vraag of de redenering met betrekking tot de discretionaire bevoegdheid klopt wanneer een vergelijking getrokken wordt met artikel 69 lid $1 \mathrm{Fw}$, zoals in het voorgaande reeds is geschetst. Zeker wanneer je bedenkt dat tegen beslissingen van de rechter-commissaris in beginsel ${ }^{24}$ hoger beroep openstaat op grond van artikel 67 lid $1 \mathrm{Fw}$. Dit zou er des te meer voor pleiten om te oordelen dat het wel degelijk een verzoekschriftprocedure betreft waarin een beschikking gegeven wordt, waartegen hoger beroep ingesteld kan worden.

\section{Afsluiting}

De hoeveelheid aanpassingen die de expertgroep heeft doorgevoerd in de handleiding en richtlijnen is in haar geheel bezien niet zo groot. De aanpassingen betreffende de door de rechter te geven aanwijzingen op grond van artikel 4:210 lid $1 \mathrm{BW}$ leiden wel tot een opmerkelijke breuk met het verleden. In de handleiding komt duidelijk naar voren dat niet om een aanwijzing kan worden verzocht en dat hoger beroep instellen tegen een gegeven aanwijzing of een juist niet gegeven aanwijzing niet mogelijk is. Het geven van aanwijzingen betreft volgens de expertgroep een discretionaire bevoegdheid van de rechter. Het is de vraag - gelet op de vele parallellen die er te trekken zijn met de vereffening in het kader van het faillissement - of dit terecht is. Wij vinden het argument dat we ons niet (enkel) op de tekst uit de wetsgeschiedenis kunnen beroepen, valide. Het niet goed onderbouwde argument dat hoger beroep instellen niet mogelijk moet zijn, zou nader toegelicht moeten worden. In welke vorm de aanwijzing wordt 
gegoten, komt wat minder duidelijk naar voren. De gehele toelichting in samenhang lezend, lijkt het erop dat de aanwijzing in de vorm van een brief wordt gegeven, maar bij een volgende versie van de handleiding en richtlijnen zou het mooi zijn wanneer dit ook expliciet wordt opgenomen in beide documenten, uiteraard in het geval het standpunt van de expertgroep hieromtrent niet wijzigt. Voor nu zijn wij benieuwd naar hoe de praktijk de nieuwe richtlijnen en handleiding zal gaan toepassen. Gaan kantonrechters massaal brieven sturen en geen beschikkingen meer geven? Krijgen we hogerberoepsprocedures waarbij appel ingesteld wordt tegen een aanwijzing in de vorm van een brief? Worden verzoeken tot het geven van een aanwijzing standaard afgewezen? Gaan kantonrechters actief gebruik maken van hun discretionaire bevoegdheid? Komt de Hoge Raad hier nog aan te pas? We wachten het af. In ieder geval is duidelijk hoe de expertgroep erover denkt. De praktijk kan aan de slag met de nieuwe aanwijzingen over de aanwijzing. 